\section{Изучение кинетики высвобождения липофильных ингредиентов из капсул с использованием синтетических и природных систем}

А.А. Шарипова ${ }^{1}$, А.Б. Исаева ${ }^{1,2 *}$ С.Б. Айдарова ${ }^{1,2}$, Ж.Б. Оспанова ${ }^{3 * *}$ А.Б. Бектурсын ${ }^{3}$, А.А. Бабаев

${ }^{1}$ Satbayev University, Алматы, Казахстан Казахстанско-Британский технический университет, Алматы, Казахстан ${ }^{3}$ Казахский национальный университе им. аль-Фараби, Алматы, Казахстан *E-mail: isa-asem@mail.ru

**E-mail: zhanar.ospanova@kaznu.kz

\section{Синтетикалық және табиғи жүйелерді қолдана отырып капсулалардан липофильді ингредиенттердің бөліну кинетикасын зерттеу}

А.А. Шарипова ${ }^{1}$, А.Б. Исаева ${ }^{1,2 *}$ С.Б. Айдарова ${ }^{1,2}$, Ж.Б. Оспанова ${ }^{3 * *}$ А.Б. Бектурсын ${ }^{3}$ А.А. Бабаев

${ }^{1}$ Satbayev University, Алматы, Қазақстан ${ }^{2}$ Қазақстан-Британ техникалық университеті, Алматы, Қазақстан зəл-Фараби Қазақ ұлттық университеті, Алматы, Қазақстан *E-mail: isa-asem@mail.ru

**E-mail: zhanar.ospanova@kaznu.kz
В работе была изучена кинетика высвобождения витамина E и полифитового масла из капсул с использованием синтетических и природных систем. Высвобождение активных ингредиентов исследовали на УФ-спектрофотометре Cary 50 Cons, оснащенного программным обеспечением CaryWinUV. Кинетика высвобождения витамина $\mathrm{E}$ из капсул, стабилизированных казеинатом натрия и затем покрытых хитозаном показывает замедленное пролонгированное высвобождение $20 \%$ витамина Е в течение 1 ч, в течение 5 ч высвобождается около 45\%, в течение 48 ч около $80 \%$. Установлено, что эффективность капсулирования витамина Е выше, чем полифитового масла, высвобождение витамина Е более замедленное и пролонгированное по сравнению с полифитовым маслом. Также исследовано высвобождение витамина Е из капсул, стабилизированных синтетической системой полимер-ПАВ / витамин Е) хитозан) полистирол сульфонат PSS. Определено, что высвобождение витамина Е из капсул, стабилизированных синтетической системой (полимер-ПАВ и покрытых двумя слоями противоположно заряженных полиэлектролитов методом Layer-by-Layer) пролонгированное, в течение 1 ч - 23\% высвобождается витамина E, $70 \%$ - в течение 12 ч и 100\% - в течение 80 ч.

Ключевые слова: кинетика высвобождения; витамин Е; полифитовое масло; казеинат натрия; хитозан; метод Layer-by-Layer; полистирол сульфонат.
Жұмыста синтетикалық және табиғи жүйелерді қолдана отырып, капсулалардан Е дәрумені мен полифит майының бөліну кинетикасы зерттелді. Белсенді ингредиенттердің шығарылуы CaryWinUV бағдарламалық жасақтамасымен жабдықталған Cary 50 Cons ультракүлгін спектрофотометрінде бақыланды. Натрий казеинатымен тұрақтандырылған және содан кейін хитозанмен қапталған капсулалардан Е дәрумені шығарудың кинетикасы ұзақ уақыт бойы 20\% Е дәруменінің 1 сағат ішінде, 5 сағат ішінде 45\%, 48 сағат ішінде шамамен 80\% бөлінуін көрсетеді. Е витаминінің капсуляция тиімділігі полифит майына қарағанда жоғары екендігі анықталды, полифит майымен салыстырғанда Е витаминінің шығарылуы баяу және ұзаққа созылады. Сондай-ақ синтетикалық жүйемен полимербеттік-белсенді зат / Е дәрумені) хитозан) полистирол сульфонат PSS тұрақтандырылған капсулалардан Е дәруменінің бөлінуі зерттелді. Синтетикалық жүйемен тұрақтандырылған капсулалардан (полимер-беттік-белсенді зат және қабат-қабат бойынша қарама-қарсь зарядталған полиэлектролиттің екі қабатымен қапталған) Е бөлінуі ұзаққа созылатынь анықталды, 1 сағат ішінде - Е дәрумені 23\% құрайды. шығарылды, 70\% - 12 сағат ішінде және $100 \%$ - 80 сағат ішінде.

Түйін сөздер: бөлініп шығу кинетикасы; Е дәрумені; полифит майы; натрий казеинаты; хитозан; Layer-by-Layer әдісі; полистирол сульфонат.

\section{Study of the kinetics of the release of lipophilic ingredients from capsules using synthetic and natural systems}

A.A. Sharipova ${ }^{1}$, A.B. Issayeva ${ }^{1,2 *}$ S.B. Aidarova ${ }^{1,2}$ Zh.B. Ospanova ${ }^{3 * *}$ A.B. Bektursyn ${ }^{3}$, A.A. Babayev

${ }^{1}$ Satbayev University, Almaty, Kazakhstan ${ }^{2}$ Kazakh-British Technical University, Almaty, Kazakhstan

${ }^{3} \mathrm{Al}-$ Farabi Kazakh National University, Almaty, Kazakhstan *E-mail: isa-asem@mail.ru

**E-mail: zhanar.ospanova@kaznu.kz
In the work, the kinetics of the release of vitamin E and polyphyte oil from capsules was studied using synthetic and natural systems. The release of active ingredients was monitored on a Cary 50 Cons UV spectrophotometer equipped with CaryWinUV software. The kinetics of the release of vitamin $\mathrm{E}$ from capsules stabilized with sodium caseinate and then coated with chitosan shows a sustained prolonged release of $20 \%$ of vitamin $\mathrm{E}$ within $1 \mathrm{~h}$, within $5 \mathrm{~h}$ about $45 \%$ is released, within $48 \mathrm{~h}$ about $80 \%$. It was found that the efficiency of capsulation of vitamin $\mathrm{E}$ is higher than that of polyphyte oil, the release of vitamin $\mathrm{E}$ is more delayed and prolonged in comparison with polyphyte oil. The release of vitamin E from capsules stabilized with a synthetic system polymer-surfactant / vitamin E) chitosan) polystyrene sulfonate PSS was also investigated. It was determined that the release of vitamin E from capsules stabilized by a synthetic system (polymer-surfactant and coated with two layers of oppositely charged polyelectrolyte by the Layer-by-Layer method) is prolonged, within $1 \mathrm{~h}-23 \%$ of vitamin $\mathrm{E}$ is released, $70 \%-$ within $12 \mathrm{~h}$ and $100 \%$ - within $80 \mathrm{~h}$.

Keywords: release kinetics; vitamin E; polyphyte oil; sodium caseinate; chitosan; Layer-byLayer method; polystyrene sulfonate. 


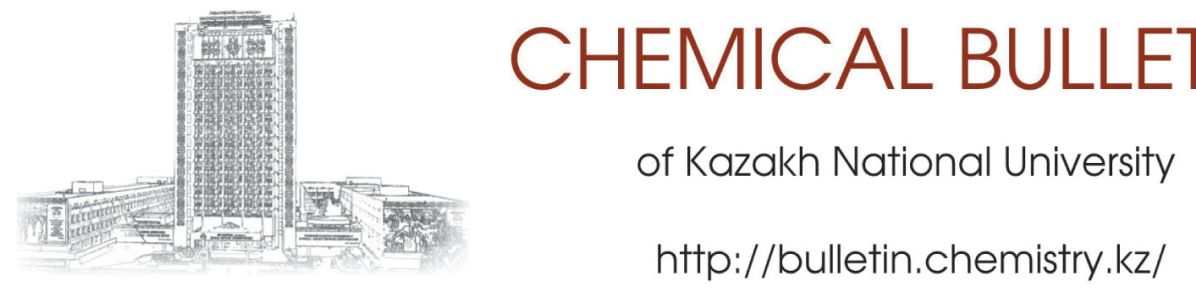

УДК 544.7 - 022.532

https://doi.org/10.15328/cb1216

\title{
Изучение кинетики высвобождения липофильных ингредиентов из капсул с использованием синтетических и природных систем
}

\author{
А.А. Шарипова ${ }^{1}$ \\ А.Б. Бектурсын ${ }^{3}$, А.А. Бабаев ${ }^{2}$ \\ С.Б. Айдарова ${ }^{1,2} \mathbb{D}$, Ж.Б. Оспанова ${ }^{3 *} \mathbb{D}$, \\ ${ }^{1}$ Satbayev University, ул. Сатпаева 22а, 050013 Алматы, Казахстан \\ ${ }^{2}$ Казахстанско-Британский технический университет, ул. Толе би 59, 050000 Алматы, Казахстан \\ ${ }^{3}$ Казахский национальный университет им. аль-Фараби, 050040 пр. аль-Фараби 71, Алматы, Казахстан \\ *E-mail: isa-asem@mail.ru \\ **E-mail: zhanar.ospanova@kaznu.kz
}

\section{1. Введение}

Одной из актуальных задач современной научноприкладной коллоидной химии и нанотехнологий является разработка перспективных эффективных технологий капсулирования активных реагентов, которые широко применяются в различных отраслях промышленности [1-7]. В этом аспекте для развития нанотехнологий и получения новых наноматериалов перспективны такие композиционные материалы, которые способны эффективно модифицировать практически важные свойства дисперсных систем.

В настоящее время наблюдается интенсивный рост исследований, посвященных получению микро- и нанокапсул, обладающих уникальными свойствами и высоким потенциалом для разработки на их основе эффективных лекарственных, фармацевтических препаратов, а также лакокрасочных материалов. Одним из методов, позволяющих получить частицы в нанометровом диапазоне, является микроэмульсионное капсулирование.

Эмульсии широко используются в фармацевтике, пищевой и других отраслях промышленности для капсулирования, солюбилизации и контролируемой доставки активных ингредиентов. Особенное внимание привлекает использование синтетических полимеров и ПАВ для стабилизации эмульсий. Для удовлетворения растущего спроса на экологические чистые компоненты, природные полимеры могут с успехом использоваться в процессе получения эмульсий.

\section{2. Эксперимент}

В работе была изучена кинетика высвобождения витамина Е и полифитового масла из капсул с использованием синтетических и природных систем.

Высвобождение активных ингредиентов исследовали на УФ-спектрофотометре Cary 50 Cons, оснащенного программным обеспечением CaryWinUV.

Спектры поглощения эмульсий капсул, содержащих витамин Е и полифитового масла в ультрафиолетовой/ видимой областях спектра, снимали с помощью двухлучевого сканирующего спектрофотометра Cary 50 Cons (Perkin-Elmer, Германия) с диапазоном длин волн 190900 HM.

Профиль высвобождения витамина Е и полифитового масла из микрокапсул изучали в 50\% водном растворе этанола ( $\left.\mathrm{H}_{2} \mathrm{O} / \mathrm{EtOH}\right)$. Микрокапсулы были помещены в диализную трубку (12000 MCOW), которая была погружена в $50 \%$ спиртовый раствор при непрерывном перемешивании (300 оборотов/мин на магнитной мешалке) при комнатной температуре. Аликвоты супернатанта (1 мл) отбирали и заменяли свежим 50\% водным раствором этанола в соответствующие интервалы времени. Супернатант, содержащий растворенный активный ингредиент, анализировали с помощью UV-VISспектроскопии.

Для построения градуировочного графика в начале записывали спектр поглощения раствора вещества и находили длину волны, соответствующую максимуму поглощения (максимум поглощения витамина $\mathrm{E}$ 
соответствует длине волны 280 нм). Затем готовили серию стандартных растворов с различным содержанием определяемого компонента и измеряли их оптическую плотность при выбранной длине волны (280 нм) и толщине слоя. Строили градуировочный график в координатах $A$ от С. В случае подчинения закону Бугера-Ламберта-Бера и при измерении оптической плотности относительно растворителя, график представляет собой прямую, проходящую через начало координат. Калибровочный график зависимости оптической плотности от концентрации витамина Е представлен на рисунке 1.

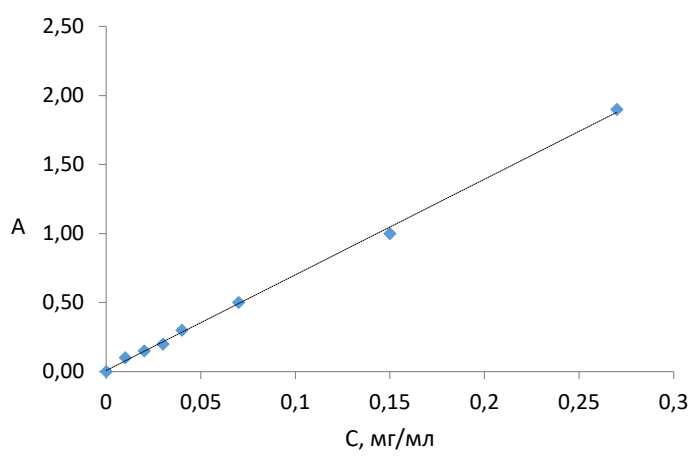

Рисунок 1 - Калибровочный график зависимости оптической плотности от концентрации витамина $\mathrm{E}$

Для количественного определения витамина Е, высвобожденного из капсул, использовали метод стандартного раствора, согласно которому измеряли оптическую плотность исследуемого раствора $A_{x}$ и по калибровочному графику находили концентрацию $C X$ вещества в растворе. Расчет концентрации $C_{x}$ проводили по формуле, исходя из закона Бугера-Ламберта-Бера:

$$
C_{x}=A_{x} \cdot C_{c m} / A_{c m}
$$

Аналогичный калибровочный график был получен для полифитового масла.

\section{3. Результаты и обсуждение}

В результате проведенных исследований выявлены оптимальные условия для капсулирования витамина E биосовместимыми системами и исследования их высвобождения: стабилизатор - $1 \%$ казеинат натрия, покрытый 1\% хитозаном методом Layer-by-Layer, концентрация витамина E - 5\%, время эмульгирования 7 мин, амплитуда 50 Гц, $\mathrm{pH}=6$. Эффективность инкапсуляции витамина Е составляет $53 \%$.

Выявлены также оптимальные условия для капсулирования полифитового масла: стабилизатор - $1 \%$ казеинат натрия, покрытый 1\% хитозаном методом Layerby-Layer, концентрация полифитового масла 10\%, время эмульгирования 3 мин, амплитуда 50 Гц, $\mathrm{pH}=4$. Эффективность капсулирования полифитового масла составила $45 \%$.

Схема получения капсул витамина Е и полифитового масла на основе М/В эмульсий, стабилизированных биосовместимыми системами представлена на рисунке 2 .

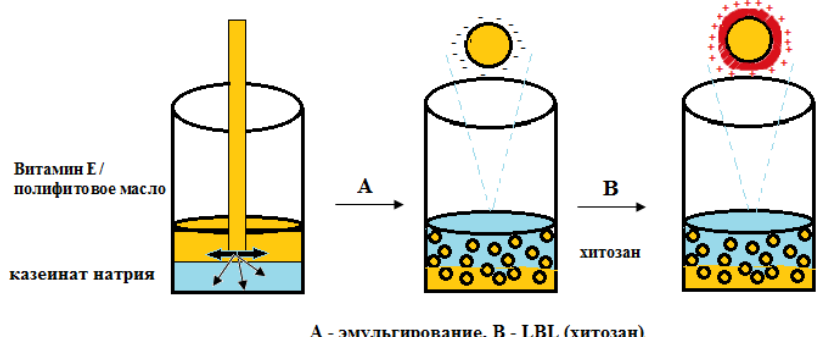

Рисунок 2 - Схема процесса получения эмульсий/капсул, содержащих активное вещество, стабилизированных $1 \%$ казеинатом натрия и покрытым биосовместимым хитозаном

Профиль высвобождения витамина Е из капсул, стабилизированных $1 \%$ казеинатом натрия, покрытым $1 \%$ хитозаном методом Layer-by-Layer представлен на рисунке 3.

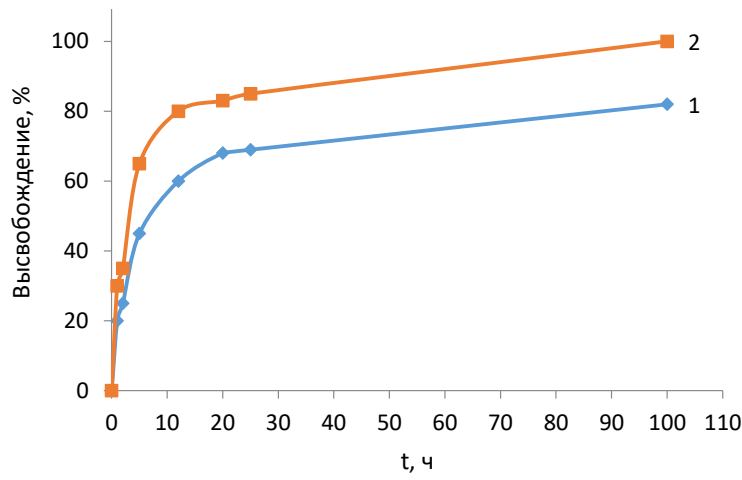

Рисунок 3 - Кинетика высвобождения активных ингредиентов (1 - витамина Е; 2 - полифитового масла)

$50 \%$ водный раствор этанола $\left(\mathrm{H}_{2} \mathrm{O} / \mathrm{EtOH}\right)$ выбран в качестве среды для высвобождения витамина E[8]. Несмотря на то, что витамин Е не растворяется в воде, добавление спирта приводит к значительному увеличению его растворимости, скорее всего, из-за неполярных взаимодействий между этанолом и молекулами витамина Е.

Кинетика высвобождения витамина E из капсул, стабилизированных казеинатом натрия и затем покрытых хитозаном показывает замедленное пролонгированное высвобождение 20\% витамина Е в течение 1 ч (рисунок 3), в течение 5 ч высвобождается около 45\%, в течение 484 около $80 \%$. 
Таблица 1 - Высвобождение активных ингредиентов из капсул

\begin{tabular}{cccc}
\hline \multirow{2}{*}{ Активный ингредиент } & \multicolumn{2}{c}{ Высвобождение активных ингредиентов, \% } \\
\cline { 2 - 4 } & В течение 1 ч & В течение 5 ч & В течение 12 ч \\
\hline Витамин Е & $20 \%$ & $45 \%$ & $65 \%$ \\
Полифитовое масло & $30 \%$ & $65 \%$ & $80 \%$ \\
\hline
\end{tabular}

Кинетика высвобождения полифитового масла из капсул, стабилизированных казеинатом натрия и далее покрытым хитозаном также показывает замедленное его высвобождение. В частности, в течение первого часа выделяется около 30\%, в течение 12 ч - $80 \%$ и в течение 48 ч происходит полное высвобождение.

Таким образом, сравнивая полученные данные установлено, что эффективность капсулирования витамина Е выше, чем полифитового масла, а также высвобождение витамина Е более замедленное и пролонгированное по сравнению с полифитовым маслом (таблица 1).

Метод многослойного капсулирования позволяет замедлить процесс высвобождения активного компонента [9], что обеспечивает терапевтически действующую концентрацию лекарственного вещества в организме в течение длительного периода времени [10]. Кроме того, многослойное капсулирование позволяет повысить устойчивость капсул для возможности их длительного хранения [11]. Была изучена кинетика высвобождения витамина E капсул, стабилизированных полимер-ПАВ комплексом и покрытых двумя слоями противоположно заряженных полиэлектролитов методом Layer-by-Layer. Схема получения микрокапсул на основе прямых M/B эмульсий, стабилизированных полимер-ПАВ и покрытых двумя слоями противоположно заряженных полиэлектролитов методом Layer-by-Layer представлена на рисунке 4.

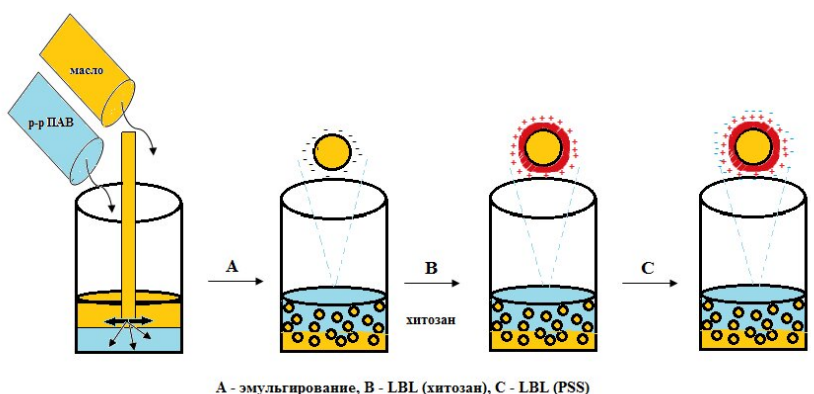

Рисунок 4 - Схема получения микрокапсул, стабилизированных синтетической системой

На рисунке 5 представлена кинетика высвобождения витамина Е из капсул, стабилизированных синтетической системой полимер-ПАВ/витамин Е) хитозан) PSS.
Кинетика высвобождения витамина Е в контрольной эмульсии показывает 100\% высвобождение витамина Е в течение 1 ч из-за нестабильности контрольной эмульсии витамина Е (рисунок 5, кривая 1).

Во втором случае, представлен профиль высвобождения витамина $\mathrm{E}$ из капсул, стабилизированных комплексом полимер/ПАВ, который показывает более постепенное высвобождение витамина Е (около 40\%) в течение 1 ч. Примерно 70\% витамина Е было обнаружено в водно-спиртовом растворе после 3 ч, а 100\% полное высвобождение достигнуто почти после 24 ч (рисунок 5, кривая 2).

Профиль высвобождения витамина E капсул, стабилизированных полимер-ПАВ и покрытых двумя слоями противоположно заряженных полиэлектролитов методом Layer-by-Layer наиболее замедленный, только 23\% витамина Е высвобождается в течение $14,70 \%$ - в течение 12 ч и 100\% - в течение 80 ч (рисунок 5, кривая 3).

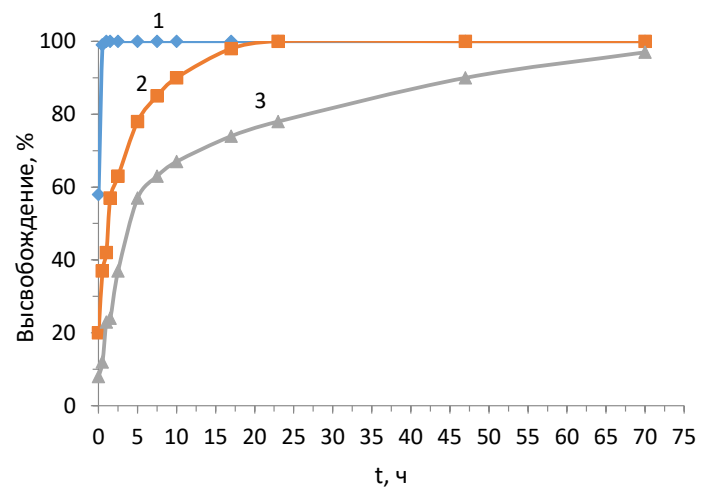

1 - контрольная эмульсия, 2 - капсулы, стабилизированные комплексом полимер/ПАВ, 3 - капсулы, стабилизированные синтетической системой полимерПАВ/витамин Е) хитозан) PSS.

Рисунок 5 - Высвобождение витамина Е в 50\% водный

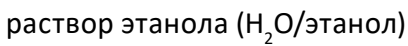

Таким образом, замедленная кинетика высвобождения витамина Е из конечных капсул, составляющая 80 ч доказывает эффективность методологии инкапсулирования, основанной на стабилизации композиций полиэлектролит-ПАВ, покрытых двумя слоями противоположно заряженных полиэлектролитов методом Layer-by-Layer. 


\section{4. Заключение}

Изучена кинетика высвобождения активных ингредиентов из капсул, основанных на прямых М/В эмульсиях, стабилизированных биосовместимыми и синтетическими системами с сочетанием метода Layer-byLayer, из капсул.

Выявлено, что кинетика высвобождения витамина $\mathrm{E}$ из капсул, стабилизированных биосистемой (казеинатом натрия и затем покрытых хитозаном) показывает замедленное пролонгированное его высвобождение, которое составляет в течение первого часа $20 \%$ витамина $\mathrm{E}$, в течение 5 ч - около 45\%, в течение 48 ч - около $8 \%$.

Установлено, что высвобождение полифитового масла из капсул, стабилизированных натуральной системой (казеинатом натрия и затем покрытым хитозаном) также показывает замедленное его высвобождение. В частности, в течение первого часа выделяется около $30 \%$, в течение 12 ч - $80 \%$ и в течение 48 ч происходит полное высвобождение.

Определено, что высвобождение E из капсул, стабилизированных синтетической системой (полимерПАВ и покрытых двумя слоями противоположно заряженных полиэлектролитов методом Layer-by-Layer) пролонгированное, в течение $14-23 \%$ высвобождается витамина Е, 70\% - в течение 12 ч и $100 \%$ - в течение 80 ч.

Таким образом, полученные результаты свидетельствуют о медленном высвобождении и пролонгированном действии активного вещества.

\section{Благодарности}

Эта работа была профинансирована Министерством образования и науки Республики Казахстан (АР09562433).

\section{Литература}

1 Sukhorukov G.B., Donath E., Davis S., Lichtenfeld H., Caruso F., Popov V.I., Mohwald H. Stepwise polyelectrolyte assembly on particle surfaces: a novel approach to colloid design // Polymers for Advanced Technologies. - 1998. - Vol.9, Is.10-11. - P.759-767.

2 Schneider G., Decher G. From functional core/shell nanoparticles prepared via layer-by-layer deposition to empty nanospheres // Nano Letters. - 2004. - Vol.4. - P.1833-1839.

3 Trojer M., Li Y., Abrahamsson C., Mohamed A., Eastoe J., Holmberga K., Nyd'ena M. Charged microcapsules for controlled release of hydrophobic actives. Part I: encapsulation methodology and interfacial properties // Soft Matter. - 2013. - Vol.9, Is.5. P.1468-1477.

4 Peter S. Given Jr. Encapsulation of Flavors in Emulsions for Beverages // Current Opinion in Colloid \& Interface Science. - 2009. - Vol.14. - P.43-47.

5 Ezhilarasi P.N., Karthik P., Chhanwal N., Anandharamakrishnan C. Nanoencapsulation Techniques for Food Bioactive Components: A Review // Food and Bioprocess Technology. - 2013. - Vol.6. - P.628-647.

6 Voigt A., Lichtenfeld H., Sukhorukov G., Zastrow H., Donath E., Baumler H. and Mohwald H. Membrane Filtration for Microencapsulation and Microcapsules Fabrication by Layer-by-Layer Polyelectrolyte Adsorption // Industrial \& Engineering Chemistry Research 38. - 1999. - Vol.38. - P.4037-4043.

7 Trojer M.A., Mohamed A., Eastoe J. A highly hydrophobic anionic surfactant at oil-water, water-polymerand oil-polymer interfaces: Implications for spreading coefficients, polymer interactions and microencapsulation via internal phase separation // Colloids and Surfaces A: Physicochemical and Engineering Aspects. - 2013. - Vol.436. - P.1048-1059.

8 Shahidi F., Abuzaytoun R. Chitin, chitosan and co-products: chemistry, production, applications and health effects in Advances in Food and Nutrition Research. - Academic Press, 2005. - Vol.49. - P.93-135.

9 Mateos-Maroto A., Abelenda-Núñez I., Ortega F., Rubio R.G., Guzmán E. Polyelectrolyte Multilayers on Soft Colloidal Nanosurfaces: A New Life for the Layer-By-Layer Method // Polymers. - 2021. - Vol.13, Is.8. - ID1221.

10 Pereira G.G., Detoni C.B., Balducci A.G., Rondelli V., Colombo P., Guterres S.S., Sonvico F. Hyaluronate nanoparticles included in polymer films for the prolonged release of vitamin $E$ for the management of skin wounds // European Journal of Pharmaceutical Sciences. - 2016. - Vol.83. - P.203-211.

11 Morais Diane J.M., Burgess J. Vitamin e nanoemulsions characterization and analysis // International Journal of Pharmaceutics. - 2014. - Vol.465, Is.1-2. - P.455-463.

\section{References}

1 Sukhorukov GB, Donath E, Davis S, Lichtenfeld H, Caruso F, et al (1998) Polyme Advan Technol 9:759-767. http://doi.org/10.1002/ (SICI)1099-1581(1998100)9:10/11\%3C759::AID-PAT846\%3E3.0.CO;2-Q

2 Schneider G, Decher G (2004) Nano Lett 4:1833-1839. http://doi.org/10.1021/nl0490826

3 Trojer M, Li Y, Abrahamsson C, Mohamed A, Eastoe J, Holmberg K, Nyd'en M (2013) Soft Matter 9:1468-1477. http://doi. org/10.1039/C2SM27275J 
4 Peter S Given Jr (2009) Curr Opin Colloid In 14:43-47. http://doi.org/10.1016/j.cocis.2008.01.007

5 Ezhilarasi PN, Karthik P, Chhanwal N, Anandharamakrishnan C (2013) Food Bioprocess Tech 6:628-647. http://doi.org/10.1007/ s11947-012-0944-0

6 Voigt A, Lichtenfeld H, Sukhorukov G, Zastrow H, Donath E, et al (1999) Ind Eng Chem Res 38:4037-4043. http://doi.org/10.1021/ ieg900925

7 Trojer MA, Mohamed A, Eastoe J (2013) Colloid Surface A 436:1048-1059. http://doi.org/10.1016/j.colsurfa.2013.08.005

8 Shahidi F, Abuzaytoun R (2005) Chitin, Chitosan, and Co-Products: Chemistry, Production, Applications, and Health Effects in Advances in Food and Nutrition Research, Academic Press. Vol.49. P.93-135. http://doi.org/10.1016/S1043-4526(05)49003-8

9 Mateos-Maroto A, Abelenda-Núñez I, Ortega F, Rubio RG, Guzmán E (2021) Polymers-Basel 13:1221. http://doi.org/10.3390/ polym13081221

10 Pereira GG, Detoni CB, Balducci AG, Rondelli V, Colombo P, et al (2016) Eur J Pharm Sci 83:203-211. http://doi.org/10.1016/j. ejps.2016.01.002

11 Morais Diane JM, Burgess J (2014) Int J Pharm 465:455-463. http://doi.org/10.1016/j.ijpharm.2014.02.034 